\title{
ASSOCIATION BETWEEN SMOKING BEHAVIOUR AND GLYCOHEMOGLOBINE LEVELS AMONG ADULT JAVANESE INDONESIAN SMOKERS
}

\author{
Christine Patramurti*), Fenty \\ Faculty of Pharmacy, Sanata Dharma University, Paingan, Maguwoharjo, Depok, Sleman, \\ Yogyakarta, 55282, Indonesia
}

Received Febuary 03, 2020; Accepted June 22, 2020

\begin{abstract}
Nicotine, the active compound in cigarettes, can cause impaired glucose metabolism by increasing insulin resistance as well as decreasing insulin secretion in $\beta$ cell pancreas. This condition can increase the risk of type 2 diabetes in human. This study aims to evaluate the effect of smoking behaviour, determined by Cigarette per Day (CPD) and smoking duration, on glychohemoglobine (HbA1c) levels of Javanese Indonesian smokers. 30 smokers were studied consisting of 7 smokers with <10 CPD, 19 smokers with 11-20 CPD and 4 smokers with 21-30 CPD. They had been smoking for more than 10 years. The whole blood sample was used to examine the HbA1c levels. The HbA1c levels were tested at Bethesda Hospital's clinic laboratories using Architect 600 instrument. The results showed that CPD and smoking duration significantly influenced $\mathrm{HbA1c}$, in which $\mathrm{F}$ count was $>\mathrm{F}$ table (370.541> 3.354) with significance $<0.05(2.35 .10-20<0.05)$ and multiple correlation coefficient $(\mathrm{R})$ of 0.982 . Therefore, based on this research finding, it was concluded that longer smoking duration and higher CPD caused higher smoker's Hbalc level.
\end{abstract}

Keywords: CPD; HbA1c; smoking behaviour; smoking duration.

\section{INTRODUCTION}

Diabetes is one of the largest global health emergencies in the $21^{\text {st }}$ century. The International Diabetes Federation has predicted that there will be an increasing prevalence of diabetics in 2033 by $2.8 \%$ over the past 20 years. In addition, the number of people affected by the disease will also increase by $57 \%$ from 382 to nearly 600 million. The prevalence of diabetes has increased in Asian countries and it has contributed to more than $60 \%$ of the world's diabetic population. Indonesia ranks the seventh highest prevalence rate of diabetes in the world after China, India, United States of America, Brazil, Mexico and Russian Federation (IDF, 2015). WHO estimates the number of patients with type 2 diabetes $(\mathrm{T} 2 \mathrm{DM})$ in Indonesia will increase significantly to 21.3 million in 2030 . The estimated number of deaths due to diabetes among adults aged 45-54 years in urban areas is $14.7 \%$ while in rural areas is $5.8 \%$ (R.I., 2009).

T2DM has been the most prevalent form of diabetes and has increased alongside cultural and societal changes. Smoking has been believed to be one of the factors that can increase the risk of diabetes. The increasing risk of diabetes to smokers has been reported in several studies. Smokers possess $45 \%$ higher risk of diabetes than nonsmokers (Willi et al., 2007). Even though empirical data have shown that smoking may cause serious health problems in some countries, production and consumption of tobacco products in several Asian countries such as China, India and Indonesia still exist until now. The prevalence of smoking among Indonesian men was $67.4 \%$, which was the highest smoking rate 
within ASEAN regions (Lian et al., 2014; Tandilittin et al., 2013). According to the Ministry of Health (2017), the percentage of Indonesian population with T2DM risk factor due to smoking activity over the age of 10 is $24.3 \%$.

Several diabetes experts, namely the International Committee of Experts, the American Diabetes Association (ADA) and the European Association for the Study of Diabetes (EASD), have recommended the use of $\mathrm{HbA} 1 \mathrm{c}$ to diagnose diabetes. HbA1c can be used to reflect average blood glucose levels over 3-4 months, providing a useful longerterm measurement of blood glucose control. Prior to the test of $\mathrm{HbAlc}$, fasting was not needed. Therefore, meal issues are not an urgent factor. Currently, HbA1c test is preferable because it can be done at any time, the value can reduce daily variation of sugar content and it is more reproducible. In 2011, ADA and WHO used HbA1c as diabetes diagnostic criteria with the following propositions; $\mathrm{HbA} 1 \mathrm{c}$ under normal circumstances was $3.5 \%-5 \%$ and diabetes was confirmed if $\mathrm{HbA} 1 \mathrm{c} \geq 6.5 \%$. If $\mathrm{HbA} 1 \mathrm{c}$ levels are between 6.0 and $6.5 \%$, it was at particularly high risk and might be considered for diabetic prevention interventions (ADA, 2011; WHO, 2011).

Nicotine, the active compound in cigarettes, is the most responsible compound for increasing blood sugar levels (Bajaj, 2012; Borowitz et al., 2008; Xie et al., 2009). Nicotine can cause impaired glucose metabolism and increase insulin resistance, which may lead to an increasing risk of developing type 2 diabetes (T2DM) (Houston et al., 2006; Willi et al., 2007). This study aims to investigate the effect of smoking behaviour, indicated by Cigarette per Day (CPD) and smoking duration, on HbA1c levels among Javanese Indonesian smokers. This research was conducted primarily in order to prevent the increase of T2DM in Indonesia.

\section{METHODS \\ Materials}

All chemicals, reagents, and solvents used during this study were analytical grade and highly pure. Ethanol $70 \%$ were purchased from Sigma (St. Louis, MO, USA) and we used sterilized water for injection from Ikaphamindo as a solvent.

\section{Instrumentations}

The $\mathrm{HbA1c}$ measurements were carried out using Arcitec 600 at Bethesda Hospital's clinic laboratories.

\section{Methods}

The study had been accomplished in 2017 and had been approved by the Ethics Committees of Medical Research Duta Wacana University, Yogyakarta, Indonesia with clearance number of 424/C.16/FK/2017. A total of 30 male healthy Javanese Indonesian smokers were recruited from Sanata Dharma University staffs who had been involved in previous studies of CYP2A6 $* 1$, CYP2A6*4, and CYP2A6 *9 genotypes. Research subjects had smoked for minimum 10 years, were not currently planning to stop smoking, were between 20 and 45 years-old, had body weight between 46 and $75 \mathrm{~kg}$ with height varying between 150 and $170 \mathrm{~cm}$, took no concurrent medications, and had no illnesses requiring investigation or treatment. Smoking status was collected based on questionnaires which requested information on the number of cigarettes smoked per day (CPD), the age at which the subject started smoking, and other tobacco products used. All of smoking subjects were cigarette smokers. Smokers with a family history of diabetes were excluded from this study.

Venous blood samples from all the subjects were collected in vacutainer tubes. The tubes were labelled and used to determine the HbA1c levels. The subjects had been given informed consent prior to participating in this study. The HbA1c examination was performed at Bethesda Hospital's clinic laboratories using Architect 600 instrument.

The data were analyzed using Microsoft Excel 2016. We conducted t-test and ANOVA test to examine the effect of smoking behaviour, determined by CPD and smoking duration, on HbA1c levels. The multi-liner regression analysis was used to examine correlation between CPD and smoking 
duration with $\mathrm{HbA1c}$. P values $<0.05$ were considered as statistically significant.

\section{RESULTS AND DISCUSSION}

Diabetes mellitus is one of serious problems on public health where many people are unaware to suffer from this disease. Diabetes in Indonesia, mostly T2DM caused by lifestyle, was growing precipitously. Smoking, another public health problem encountered by Indonesia, is one of lifestyle factors causing diabetes. The subjects involved in this study were active smokers who had smoked cigarettes for a minimum of 10 years with CPD between 8-30 cigarettes per day. According to Fagerstrom Test for Nicotine Dependence (FTND), the number of smoker's CPD is categorized into four criteria; 10 or less, 11-20, 21-30 and 31 or more cigarettes. Based on these criteria, the subjects The subjects involved in this study were active smokers who had smoked cigarettes for a minimum of 10 years with CPD between 8-30 cigarettes per day. According to Fagerstrom
Test for Nicotine Dependence (FTND), the number of smoker's CPD is categorized into four criteria; 10 or less, 11-20, 21-30 and 31 or more cigarettes. Based on these criteria, the subjects involved in this research were 30 smokers consisting of 7 smokers with CPD $<10$ cigarettes, 19 smokers with CPD between 11-20 cigarettes and 4 smokers with CPD between 21-30 cigarettes.

In another CYP2A6 genotype study, it was found not only active form CYP2A6*1 but also a non-active allele, CYP2A6*4 and CYP2A6*9 alleles in the population. The alleles frequencies among the subjects were 48.5\% (CYP2A6*1), 48.5\% (CYP2A6*4) and $3 \%$ for CYP2A6*9 respectively (Patramurti and Fenty, 2019). All subjects were categorized as slow metabolizers with 28 subjects had a CYP2A6*1/*4 genotype and two subjects had CYP2A6*1/*4/*9 genotype. CYP2A6 is an enzyme responsible for nicotine metabolism, and it transforms nicotine into inactive form, i.e., cotinine and 3hydroxycotinine (Figure 1).

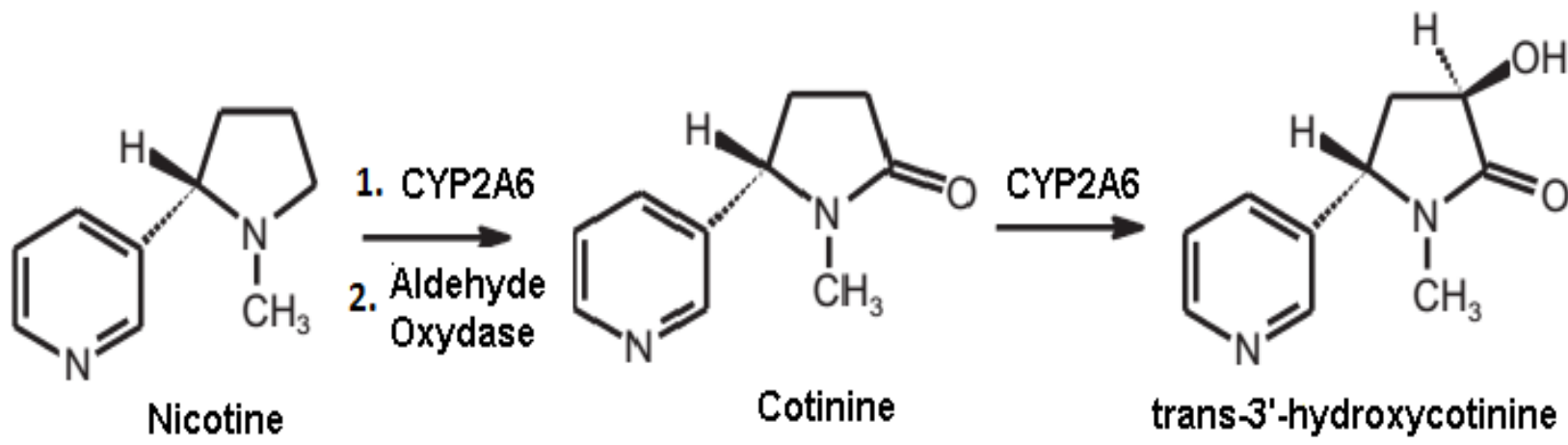

Figure 1. The main metabolism of nicotine mediated by CYP2A6 
Table 1. Characteristics and distribution of $\mathrm{HbA} 1$ content test subjects

\begin{tabular}{lccc} 
& \multicolumn{3}{c}{ Characteristics } \\
\cline { 2 - 4 } Distribution & CPD & Smoking Duration (year) & $\operatorname{HbA}_{1 \mathrm{c}}(\%)$ \\
\hline Mean \pm SD & $14 \pm 1$ & $23,57 \pm 1,22$ & $5,28 \pm 0,082$ \\
\hline Range & $6-30$ & $14-36$ & $4,83-7,16$ \\
\hline Median & 12 & 23,5 & 5,28 \\
\hline
\end{tabular}

The polymorphic form of CYP2A6 in the subjects will lead to a decreasing CYP2A6 activity in metabolizing nicotine. Slow metabolizers of nicotine will decrease nicotine metabolism. Furthermore, increasing exposure to nicotine often leads to increasing nicotine levels in the blood and creates increasing blood sugar levels. According to Liu et al. (2011), smokers categorized as slow metabolizers or poor metabolizers (having alleles $* 4$ and $* 9$ ) are more susceptible to T2DM than smokers categorized as normal metabolizers or intermediate metabolizers.

The risk of T2DM in this study was expressed by $\mathrm{HbA} 1 \mathrm{c}$ parameters. According to ADA (2014) HbA1c levels are classified into 3 groups, i.e. normal $(<5.7 \%)$, prediabetes $(5.7$ - 6.4\%) and diabetes $(\geq 6.5)$. The smokers' HbA1c levels will be higher than those nonsmokers (Jyothirmayi et al., 2013; Nilsson, et al., 2004; Padhy et al., 2015; Vlassopoulos, Lean et al., 2013). The characteristics of the subjects covering CPD, duration of smoking, and distribution of HbA1c levels are shown in table 1.

From table 1, it can be seen that the average CPD is 14 cigarettes per day. All subjects had been smoking for more than 10 years, meaning that each subject had been exposed to nicotine for a long time. The average $\mathrm{HbA1c}$ levels in all the 30 subjects were still in normal conditions with mean scores $5.28 \pm 0.082 \%$, respectively. The range of $\mathrm{HbA1c}$ levels was 4.83-7.16. It showed that there were some subjects with diabetic condition. In the measurement of $\mathrm{HbA} 1 \mathrm{c}$ levels, it was revealed that $\mathrm{HbA} 1 \mathrm{c}$ levels of 25 test subjects were still normalized within range of $4.83-5.56 \% ; 4$ subjects were identified in prediabetic condition within range of 5.7$5.97 \%$ and 1 subject had diabetes with $\mathrm{HbA} 1 \mathrm{c}$ level of $7.16 \%$. These conditions indicate that smoking behaviour affects HbA1c levels which can lead to the occurrence of T2DM disease. This finding is in line with several studies which reveal the association between active smoking and T2DM incidence worldwide (Hang, 2011; Jee et al., 2010; Kowall et al., 2010; Peter et al., 2014; Saeed, 2012). In addition, several other studies have also shown that exposure to environmental tobacco smoke (ETS) which contain nicotine towards passive smokers can also increase the risk of T2DM (Wang et al., 2013; Yeh et al., 2010).

Smoking behaviour in this study was observed from two elements namely CPD and duration of smoking. The effect of CPD and duration of smoking on HbA1c levels was partially analyzed using $t$ test. In $t$ test conducted on each variable, the $t$ value of CPD was $>\mathrm{t}$ table (3.689> -2.0480) with significance $<0.05(0.001<0.05)$. Likewise, the $\mathrm{t}$ value of duration of smoking was $>\mathrm{t}$ table (8.586> -2.048) with significance $<0.05$ $(0.000<0.05)$. Based the $t$ test on each variable, it can be concluded that both CPD and duration of smoking can partially influence $\mathrm{HbA1c}$ levels. Due to these findings, the analysis was continued using ANOVA test which would observe the effect of CPD and duration of smoking on HbAlc levels simultaneously. Anova test shows that $\mathrm{F}$ value was > F table $(370.541>3.354)$ with significance $<0.05(2.35 .10-20<0.05)$. This suggests that $\mathrm{CPD}$ and long smoking have a 
simultaneously significant effect on $\mathrm{HbA1c}$ levels.

The relationship between smoking behaviour, e.g. CPD and smoking duration, and $\mathrm{HbA1c}$ levels in this research was analyzed by multiple correlations using correlation coefficient parameter R. There was a significant correlation between $\mathrm{CPD}$ and smoking duration with $\mathrm{HbA1c}(\mathrm{R}=0.982, \mathrm{P}<$ $0.001)$. This result indicated that there was a statistically close relationship of CPD and smoking duration with HbA1c levels. The R value in this study was positive which means that CPD, smoking duration, and smokers' $\mathrm{HbA1c}$ levels have positive correlation. These results suggest that the risk of T2DM indicated by $\mathrm{HbA} 1 \mathrm{c}$ will increase with interaction of cigarettes smoked and smoking duration. Higher risk of T2DM had been observed in smokers who started smoking at age 18 years old or younger. Starting smoking at a younger age might be associated with greater dependence and heavy smoking patterns (Kawakami et al., 1997). These results also support many other previous studies which state that the more cigarettes a smoker smokes, the higher the T2DM risk is (Foy et al., 2005; Liu et al., 2011; Nakanishi et al, 2000; Will et al., 2001). The $\mathrm{R}$ square for the regression analysis was 0.963 . This means that the percentage contribution of CPD and smoking duration to HbA1c levels was $96.3 \%$ while the rest $3.7 \%$ was related to other variables which were not included in this study.
The relationship between smoking behaviour, which is indicated by CPD and smoking duration, and $\mathrm{HbA1c}$ levels was formulated by the following equation: $\mathrm{Y}=$ $0.106 \mathrm{X} 2+0.152 \mathrm{X} 1$, where: $\mathrm{Y}$ is HbA1c, $\mathrm{X} 1$ is $\mathrm{CPD}$, and $\mathrm{X} 2$ is the duration of smoking. Based on this equation, it can be seen that the magnitude of the influence of CPD and smoking duration on $\mathrm{HbA} 1 \mathrm{c}$ levels is for as much as 0.106 and 0.152 respectively. Thus, if it is assumed that the duration of smoking is constant, each cigarrete smoked will cause an increase on $\mathrm{HbA} 1 \mathrm{c}$ levels for as much as $0.106 \%$. On the other hand, if CPD does not change, each year of smoking duration will contribute to the increase of HbA1c level for as much as $0.152 \%$. The relationship curve between CPD and duration of smoking with $\mathrm{HbA} 1 \mathrm{c}$ levels is illustrated in the following figure 2. Based on those equations, prediabetic condition of a smoker will occur at least if the number of cigarettes smoked per day is as many as 20 cigarettes with a minimum smoking duration of 25 years. Meanwhile, diabetic condition of a smoker will occur at least if the number of cigarettes smoked per day is as many as 20 cigarettes with a minimum smoking duration of 29 years. Based on these results, chronic cigarette smokers will have a high risk of T2DM. Therefore, it is possible for smokers who smoke less than 20 cigarettes per day to be exposed to T2DM if they never stop their smoking habit. 


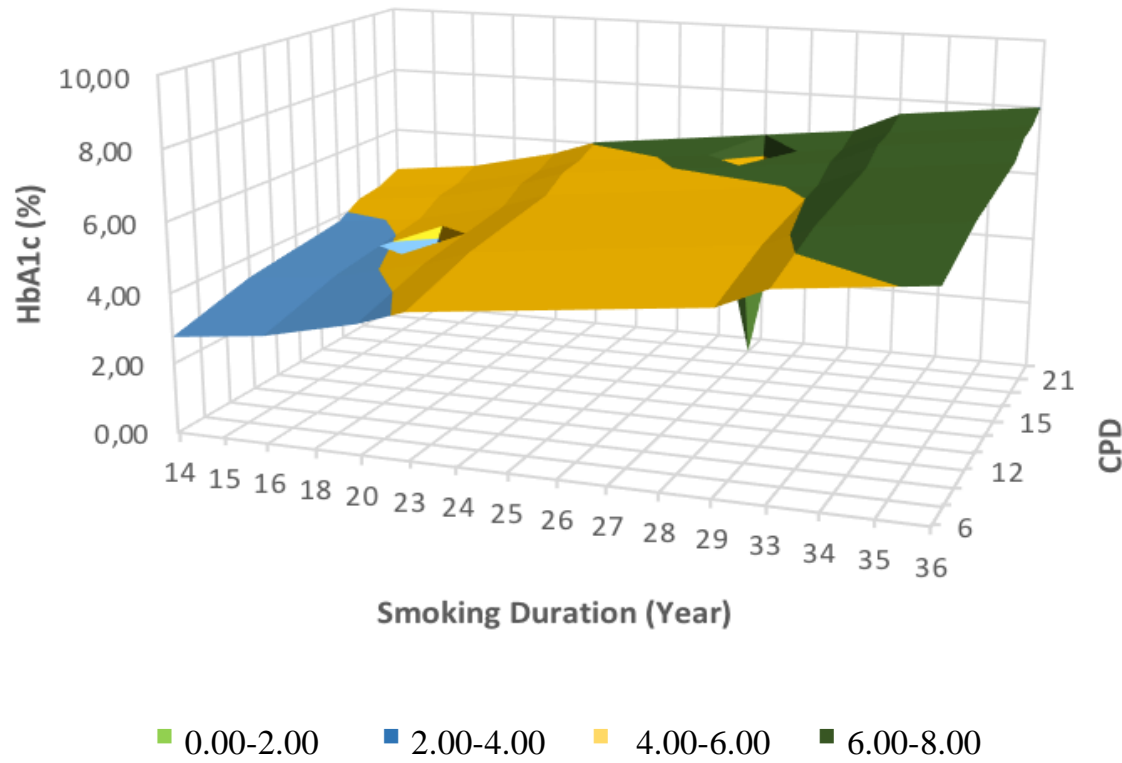

Figure 2. Relationship curve between CPD and duration of smoking with HbA1c levels. The colors show predicted $\mathrm{HbA} 1 \mathrm{c}$ value caused by interaction of smoking duration and CPD.

Nicotine, the active compound in cigarette, could decrease insulin sensitivity. In human skeletal muscle and muscle cell cultures, nicotine could interact with nicotinic acetylcholine $\alpha 1$ receptors. Due to this interaction, mammalian target of rapamycin (mTOR/p70S6) and insulin receptor substrate1(IRS-1) Ser636 phosphorylation will be activated and it causes insulin resistance or impairment of pancreatic $\beta$ cells which lead to induced insulin resistance inhibit and inhibit insulin secretion insulin (Bajaj, 2012; Bergman et al., 2012). Once insulin resistance occurs, the absorption of glucose in the tissue will be disrupted and the blood glucose levels will increase. Other than this, nicotine can also inhibit the secretion of insulin. The effect of nicotine on insulin secretion is caused by an interaction of nicotine to nicotinic acetylcholine receptors on $\beta$-cells and it will increase apoptosis of islet $\beta$-cells (Xie et al., 2009). Due to this condition, the occurrence of long-lasting exposure to nicotine in a smoker will increase the risk of T2DM disease.

Some meta-analysis studies have shown that nicotine exposure over long periods will lead to increased metabolic syndrome (Chang, 2012; Harris et al., 2016; Sun et al., 2012). Smoking is known to reduce body weight; it is linked with central obesity. Stadler et al. (2014) find that higher triglycerides and lower
High Density Lipoprotein (HDL) cholesterol which play role as major determinants in the development of T2DM in predisposed individuals can be triggered by chronic smoking. Nicotine can rise the concentration of free fatty acids in a smoker's blood by triggering an increasement in the breakdown of fats (lipolysis). This chronic rise in the concentration of fatty acids unfavorably affects insulin sensitivity and insulin secretion through direct effects on liver, pancreas and muscle. It has also been recommended that the distribution of a smoker's body fat has been directly influenced by chronic tobacco smoking (Targher, 2005; Loria et al., 2013). Further studies are needed to explore the role of association between triglycerides and HDL levels with HbA1c among Javanese Indonesian smokers.

Based on these results, we concluded that an important aspect to avoid T2DM is a prevention of smoking in early life. According to Bergman et al. (2012), insulin resistance and sensitivity caused by nicotine are reversible with smoking cessation. Therefore, to prevent the occurrence of diabetes, a smoker must stop smoking activities. Some other studies suggest that it is important to motivate smokers particularly with diabetes to stop smoking than general smoker population (Reinhard et al., 2006; Cho et al., 2009; 
Nilsson et al., 2014; Luo et al., 2013). The form of CYP2A6 allele owned by a person will affect whether it is easy for a smoker to quit smoking. Several studies conducted on adult smokers show that smokers with inactive allele types (CYP2A6*4 or *9) have less number of CPD and lower tendency to cigarette dependence compared to smokers who have active allele type (CYP2A6 * 1) (Chenoweth et al., 2013; O'Loughlin, 2004; Schoedel et al., 2004). In addition, smokers with inactive alleles have a tendency to quit smoking more easily (Ando et al., 2003; Ariyoshi et al., 2002; Fujieda et al., 2004; Minematsu et al., 2006; Rao et al., 2000). According to Padmawati et al. (2009), as much as $65 \%$ of subjects tested T2DM in Yogyakarta had a history of smoking before they were diagnosed with T2DM, even some patients with T2DM still smoked regardless of the risks. This was due to the absence of integrated effort from related parties to seek program to stop smoking. In Indonesia, where there are a high consumption rate of cigarette and a rapidly increasing prevalence of diabetes, we conclude that reducing the burden of T2DM can be done by cigarette cessation strategies which might pose some advantages. The burden illness caused by smoking will be reduced if health professionals encourage smoking cessation. Future study is required to further explain the relation between smoking cessation and prevalence of T2DM.

There are several important limitations in this study. The confounding factors like obesity, physical activity, and dietary factors have not been investigated. Further study is needed to investigate clinical significance of the result of this research. These results support other studies stating that smoking leads to increasing blood glucose levels and HbA1c levels which may lead to T2DM if smoking is not controlled.

\section{CONCLUSION}

In conclusion, our study suggests that interaction between the number of cigarettes smoked and smoking duration is strongly and independently associated with the risk of T2DM in smokers indicated by HbAlc.
Chronic smokers, either light or intermediate smokers, who have been classified as slow and poor metabolizer genotypes will have high risk to suffer from T2DM. There are several limitations in this study in which several possible contributing variables have not yet been included. Those variables might be confounding to our results, for example obesity, physical activity, dietary factors and biochemical variation such as plasma nicotine levels or total urinary nicotine equivalents.

\section{ACKNOWLEDGEMENT}

This study was supported by a grant from Lembaga Penelitian dan Pengabdian Masyarakat (research and community service institution), Sanata Dharma University.

\section{REFERENCES}

ADA. 2011. Standards of Medical Care in Diabetes. Diabetes Care, 34, S11-S61.

ADA. 2014. Standards of Medical Care in Diabetes. Diabetes Care, 37, S14-S80.

Ando, M., Hamajima, N., Ariyoshi, N., Kamataki, T., Matsuo, K., Ohno, Y. 2003. Association of CYP2A6 gene deletion with cigarette smoking status in Japanese adults. Journal of Epidemiology, 13(3), 176-181.

Ariyoshi, N., Miyamoto, M., Umetsu, Y. 2002. Genetic Polymorphism of CYP2A6 Gene and Tobacco-induced Lung Cancer Risk in Male Smokers Genetic Polymorphism of CYP2A6 Gene and Tobacco-induced Lung Cancer Risk in Male Smokers. Cancer Epidemiol Biomarkers Prev, 11, 890-894.

Bajaj, M. 2012. Nicotine and Insulin Resistance: When the Smoke Clears. Diabetes, 16, 3078-3080. 
Bergman, B. C., Perreault, L., Hunerdosse, D., Kerege, A., Playdon, M., Samek, A. M., Eckel, R. H. 2012. Novel and Reversible Mechanisms of Smoking-Induced Insulin Resistance in Humans. Diabetes, 1-11.

Borowitz, J.L., Isom, G.E. 2008. Toxicological Highlight Nicotine and Type 2 Diabetes. Toxicol. Sci., 103(2), 225-227.

Chang, S.A. 2012. Smoking and Type 2 Diabetes Mellitus. Diabetes Metabolism Journal, 36(6), 399-403.

Chenoweth, M.J., O’Loughlin, J., Sylvestre, M.-P., Tyndale, R. F. 2013. CYP2A6 Slow Nicotine Metabolism is Associated with Increased Quitting by Adolescent Smokers. Pharmacogenet. Genomics., 23(4), 232-5.

Cho, N. H., Chan, J.C.N., Jang, H.C., Lim, S., Kim, H.L., Choi, S.H. 2009. Cigarette Smoking is An Independent Risk Factor for Type 2 Diabetes: a Four-Year Community-Based Prospective Study. $J$. Clin. Endocrinol., 71, 679-685.

Foy, C.G., Bell, R.A., Farmer, D.F., Goff, D. C., Wagenknecht, L.E. 2005. Smoking and Incidence of Diabetes Among U.S. Adults Findings from the Insulin Resistance Atherosclerosis Study. Diabetes Care, 28(10), 2501-2507.

Fujieda, M., Yamazaki, H., Saito, T., Kiyotani, K., Gyamfi, M.A., Sakurai, M., AkitaDosaka, H., Sawamura, Y., Yokota, J., Kunitoh, H., Kamataki, T. 2004. Evaluation of CYP2A6 Genetic Polymorphisms as Determinants of Smoking Behavior and Tobacco-Related Lung Cancer Risk in Male Japanese Smokers. Carcinogenesis, 25(12), 24512458.

Hang, L.U.Z. 2011. Association Between Passive and Active Smoking and Incident Type 2 Diabetes in Women. Diabetes Care, 34, 892-897.

Harris, K. K., Zopey, M., Friedman, T.C. 2016. Metabolic Effects of Smoking Cessation. Nature Reviews. Endocrinology, 12, 299-308.

Houston, T. K., Person, S.D., Pletcher, M. J., Liu, K., Iribarren, C., Kiefe, C. I. 2006.
Active and Passive Smoking and Development of Glucose Intolerance among Young Adults in a Prospective Cohort: CARDIA Study. BMJ, 332(7549), 1064-1069.

IDF. 2015. IDF Diabetes Atlas (Seventh Ed). Karakas: Karakas Print. www.diabetesatlas.org. (accessed 12.10.19).

Jee, S. H., Foong, A.W., Hur, N. W., Samet, J. M. 2010. Smoking and Risk for Diabetes Incidence and Mortality in Korean Men and Women. Diabetes Care, 33(12), 2567-2572.

Jyothirmayi, B., Kaviarasi, S., William, E. 2013. Study of Glycated Hemoglobin in Chronic Cigarette Smokers. Medical Science, 5(1), 4-6.

Kawakami, N., Takatsuka, N., Shimizu, H., Ishibashi, H. 1997. Effects of Smoking on the Incidence of Non-lnsulindependent Diabetes Mellitus. American Journal of Epidemiology, 145(2), 103109.

Kowall, B., Rathmann, W., Strassburger, K., Heier, M., Holle, R., Thorand, B., Giani, G., Peters, A., Meisinger, C. 2010. Association of passive and active smoking with incident type 2 diabetes mellitus in the elderly population: the KORA S4 / F4 cohort study. Eur J Epidemiol. 25(6), 393-402.

Lian, T.Y., Dorotheo, U. 2014. The ASEAN Tobacco Control Atlas Second Edition. Bangkok: SEATCA. www.seatca.org (accessed 12.10.19).

Liu, T., Chen, W.-Q., David, S. P., Tyndale, R. F., Wang, H., Chen, Y.-M., Yu, Q.-X., Chen, W., Zhou, Q., Ling, W.-H. 2011. Interaction Between Heavy Smoking and CYP2A6 Genotypes on Type 2 Diabetes and Its Possible Pathways. European Journal of Endocrinology, 165, 961-967.

Loria, P., Lonardo, A., Anania, F. 2013. Liver and Diabetes. A Vicious Circle. Hepatol Res., 43(1), 51-64.

Luo, J., Rossouw, J., Tong, E., Giovino, G. A., Lee, C. C., Chen, C., Ockene, J.K., Qi, L., Margolis, K. L. 2013. Smoking and Diabetes: Does the Increased Risk Ever 
Go Away? American Journal of Epidemiology, 178(6), 937-945.

Minematsu, N., Nakamura, H., Furuuchi, M., Nakajima, T., Takahashi, S., Tateno, H., Ishizaka, A. 2006. Limitation of Cigarette Consumption by CYP2A6*4, *7 and *9 polymorphisms. The European Respiratory Journal, 27, 289-292.

Nakanishi, N., Nakamura, K., Matsuo, Y., Suzuki, K., Tatara, K. 2000. Cigarette Smoking and Risk for Impaired Fasting Glucose and Type 2 Diabetes in MiddleAged Japanese Men. Annals of Internal Medicine, 133, 183-191.

Nilsson, P. M., Ardanaz, E., Gavrila, D., Agudo, A. 2014. Smoking and LongTerm Risk of Type 2 Diabetes: The EPIC- InterAct Study in European Populations. Diabetes Care, 37, 3164 3171.

Nilsson, P.M., Gudbjörnsdottir, S., Eliasson, B., Cederholm, J. 2004. Smoking is Associated with Increased HbA1c Values and Microalbuminuria in Patients with Diabetes - Data from The National Diabetes Register in Sweden. Diabetes Metabolism, 30, 261-268.

O'Loughlin, J. 2004. Genetically Decreased CYP2A6 and The Risk of Tobacco Dependence: A Prospective Study of Novice Smokers. Tobacco Control, 13, 422-428.

Padhy, S., Dash, H.S. 2015. Study of Lipid Profile and Glycosylated Hemoglobin in Smokers. Medical Science, 5(6), 519520.

Padmawati, R.S., Ng, N., Prabandari, Y. S., Nichter, M. 2009. Smoking among Diabetes Patients in Yogyakarta, Indonesia : Cessation Efforts are Urgently Needed. Trop. Med. Int. Health, 14(4), 412-419.

Patramurti, C., Fenty, 2019. Genetic Polymorphism of Cytochrome P450 2A6 Allele * 4 and * 9: Study on Glycohemoglobine Level Among Javanese Indonesian Smokers. PSR, 6(2), 82-88.

RI, K.K. 2009. Tahun 2030 Prevalensi Diabetes Melitus di Indonesia Mencapai
21,3 Juta Orang. www.depkes.go.id (accessed 8.8.19).

Rao, Y., Hoffmann, E. W. A., Zia, M., Bodin, L., Zeman, M., Sellers, E. M., Tyndale, R. F. 2000. Duplications and Defects in the CYP2A6 Gene: Identification, Genotyping, and In Vivo Effects on Smoking. Mol. Pharmacol, 58(4), 747755.

Reinhard H.A., Becker, S.S., Annke D. Frick, R.J.F. 2006. The Effect of Smoking Cessation and Subsequent Resumption on Absorption of Inhaled Insulin. Diabetes Care, 29(2), 277-282.

Saeed, A.A. 2012. Association of Tobacco Products Use and Diabetes MellitusResults of a National Survey Among Adults in Saudi Arabia. Balkan Med J, 29, 247-251.

Schoedel, K.A, Hoffmann, E.B., Rao, Y., Sellers, E.M., Tyndale, R.F. 2004. Ethnic Variation in CYP2A6 and Association of Genetically Slow Nicotine Metabolism and Ssmoking in Adult Caucasians. Pharmacogenetics, 14, 615-626.

Stadler, M., Tomann, L., Storka, A., Wolzt, M., Peric, S., Bieglmayer, C., Pacini, G., Dickson, S.L., Brath, H., Bech, P., Prager, R., Korbonits, M. 2014. Effects of Smoking Cessation on b-cell Function, Insulin Sensitivity, Body Weight, and Appetite. Eur J of Endocrinology, 170, 219-227.

Sun, K., Liu, J., Ning, G. 2012. Active Smoking and Risk of Metabolic Syndrome: A Meta-Analysis of Prospective Studies. Plos One, 7(10), e47791.

Tandilittin, H., Luetge, C. 2013. Civil Society and Tobacco Control in Indonesia: The Last Resort. Open Ethics Journal, 7(1), 11-18.

Targher, G. 2005. How Does Smoking Affect Insulin Sensitivity? Diabetes Voice, 50, 23-25.

Vlassopoulos, A., Lean, M.E., Combet, E. 2013. Influence of Smoking and Diet on Glycated Haemoglobin and "PreDiabetes" Categorisation: A Cross- 
Sectional Analysis. BMC Public Health, 13, 10131020.

Wang, Y., Ji, J., Liu, Y., Deng, X., He, Q. 2013. Passive Smoking and Risk of Type

2 Diabetes: A Meta- Analysis of Prospective Cohort Studies. Plos One, 8(7), 1-6.

WHO. 2011. Use of Glycated Haemoglobin (HbA1c) in the Diagnosis of Diabetes Mellitus. Geneva.

Will, J. C., Galuska, D.A., Ford, E.S., Calle, E. E. 2001. Cigarette Smoking and Diabetes Mellitus: Evidence of A Positive Association from A Large Prospective Cohort Study. International Journal of Epidemiology, 30, 540-546.
Willi, C., Bodenmann, P., Ghali, W. A., Faris, P. D., Cornuz, J. 2007. Active Smoking and The Risk of Type 2 Diabetes: A Systematic Review and Meta-Analysis. JAMA, 298(22), 2654-2664.

Xie, X., Liu, Q., Wu, J., Wakui, M. 2009. Impact of Cigarette Smoking in Type 2 Diabetes Development. Acta Pharmacol Sin, 30(6), 784-787.

Yeh, H.-C., Duncan, B.B., Schmidt, M.I., Wang, N.-Y., Brancati, F.L. 2010. Smoking, Smoking Cessation, and Risk for Type 2 Diabetes MellitusA Cohort Study. Annals of Internal Medicine, 152(1), 10-17. 